\section{CCHEST}

'Department of General Practice, University College London Hospitals NHS

Foundation Trust, London, UK ${ }^{2}$ Department of Respiratory Medicine, Basildon University Hospital NHS Trust, Basildon, UK ${ }^{3}$ Department of Cardiothoracic Surgery, Basildon University Hospital NHS Trust, Essex, UK

\section{Correspondence to}

Dr Gayatri Raghuram, University College London Hospitals NHS Foundation Trust, London, UK; gayatriraghuram3@gmail.com

GR, DM, KP and SB contributed equally.

Received 5 August 2017 Revised 21 November 2017 Accepted 27 November 2017 Published Online First 6 December 2017

\title{
Unexpected migration
}

\section{Gayatri Raghuram, ${ }^{1}$ Dipak Mukherjee, ${ }^{2}$ Kanwar Pannu, ${ }^{2}$ Sudhir Bhusari ${ }^{3}$}

A 79-year-old man had presented to his general practitioner with a non-resolving pneumonia. $\mathrm{He}$ was treated with three courses of antibiotics after which a chest radiograph (figure 1) showed right lower zone opacity with an effusion raising concerns of underlying malignancy. He was referred urgently to the respiratory team via the suspected cancer pathway. A staging CT scan of chest and liver (figure 1) was requested. The staging CT chest and liver described a focal mass-like consolidation in the subpleural region of the right middle lobe and an ovoid well-circumscribed lesion within the epicentre of the consolidation demonstrating laminated patterns of calcification.

The patient had undergone a complicated laparoscopic cholecystectomy 6 months prior to this presentation. A CT abdomen then had shown clear lung bases. The intrathoracic lesion seen on the staging CT was morphologically very similar to the gallstone identified on the abdominal CT scan (figure 2) prior to the laparoscopic cholecystectomy. His case was discussed in the lung multidisciplinary team meeting (MDT) and he was referred to the cardiothoracic surgeons for consideration of video-assisted thoracoscopic (VATS) surgery. He eventually required a right thoracotomy and middle lobectomy. The histopathological evaluation showed an impacted gallstone measuring $40 \mathrm{~mm}$ in the anteroinferior aspect of the lobe.

In summary, he was identified to have an ectopic gallstone in the lung. Although rare, cases of ectopic gallstones in the lung after laparoscopic cholecystectomy have been reported in
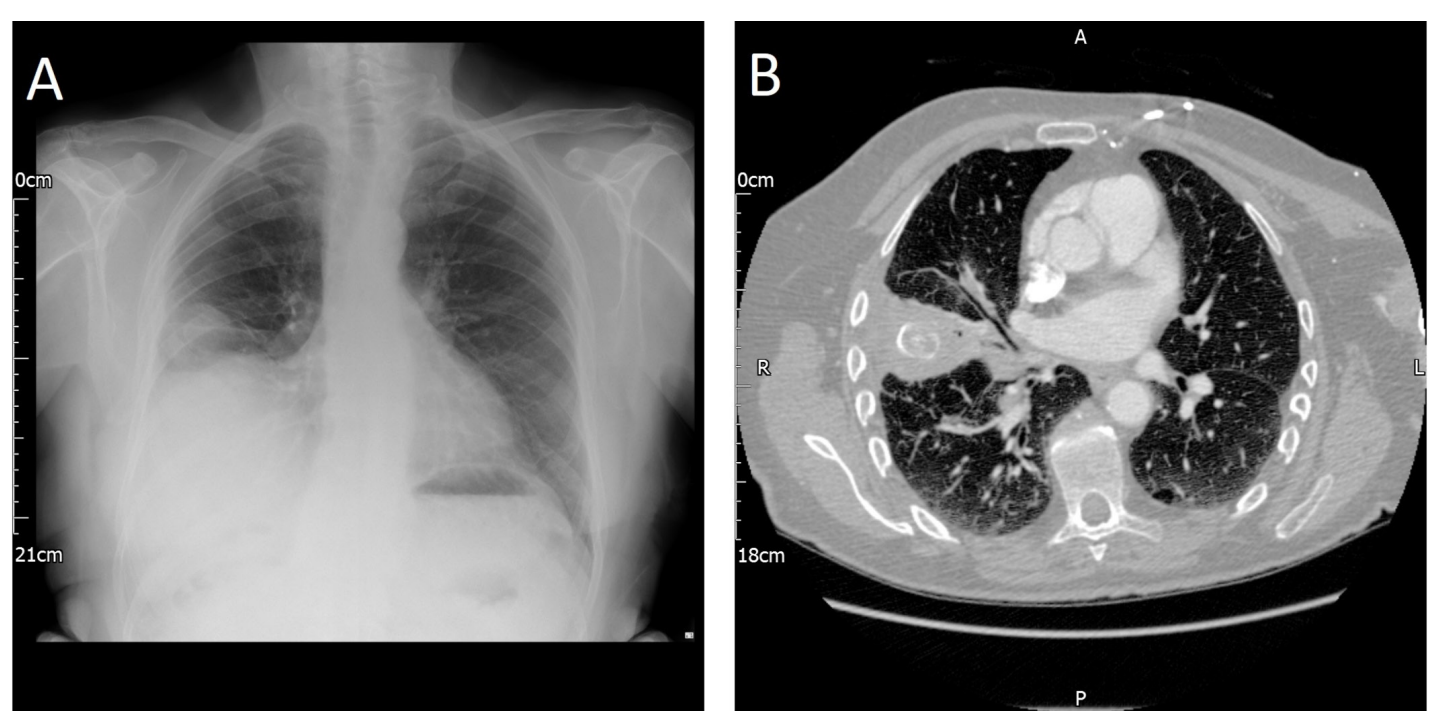

Figure 1 (A) Chest radiograph demonstrating right-sided pleural effusion, (B) CT scan of the chest and liver showing consolidation of the right middle lobe and an opacification.

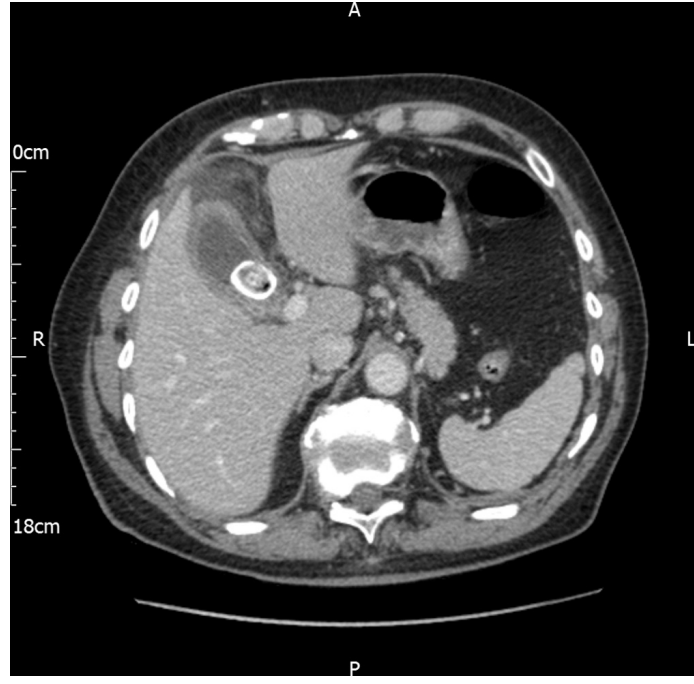

Figure 2 CT scan of the abdomen and pelvis showing cholelithiasis.

the literature. Migration of stones spilled into the peritoneum during laparoscopic cholecystectomy or from gallbladder perforation can cause complications secondary to the stones eroding through weaknesses in the diaphragm. ${ }^{1}$ Ectopic gallstones have been reported within the small bowel, aorta, ovaries and many other unusual locations. ${ }^{2}$ Within the lung, these gallstones are most commonly found in the right lower lobe and cause symptoms of haemoptysis and/or cholelithoptysis. ${ }^{3}$ Successful management has included antibiotics, bronchoscopy, wedge resection and lobectomy.

To cite: Raghuram G, Mukherjee D, Pannu K, et al. Thorax 2018;73:689-690. 
This case highlights the importance of abdominal surgical history taking in patients with lung masses and reminds clinicians to think of alternative diagnoses in a patient with a history of recent laparoscopic cholecystectomy.

Contributors DM, KP and SB managed the patient. GR prepared the manuscript. $\mathrm{DM}, \mathrm{KP}$ and $\mathrm{SB}$ revised the manuscript. All authors have contributed and are in agreement with the content of the manuscript.

Competing interests None declared.

Patient consent Obtained.
Provenance and peer review Not commissioned; externally peer reviewed.

(c) Article author(s) (or their employer(s) unless otherwise stated in the text of the article) 2018. All rights reserved. No commercial use is permitted unless otherwise expressly granted.

\section{REFERENCES}

1 Fontaine JP, Issa RA, Yantiss RK, et al. Intrathoracic gallstones: a case report and literature review. JSLS 2006;10:375-8.

2 Luu MB, Deziel DJ. Unusual complications of gallstones. Surg Clin North Am 2014;94:377-94.

3 Zhang Q, Wang X, Yan C, et al. Gallstone ectopia in the lungs: case report and literature review. Int J Clin Exp Med 2014;7:4530-3. 